\title{
Pathogenicity and Ultrastructural Studies of the Mode of Penetration by Phoma strasseri in Peppermint Stems and Rhizomes
}

\author{
BEATA ZIMOWSKA* \\ Department of Plant Pathology and Mycology, University of Life Sciences, Lublin, Poland \\ Received 15 February 2012, revised, accepted 19 september 2012
}

\author{
Abstract
}

Pathogenicity and ultrastructural investigation of the inoculation of peppermint stems and rhizomes with Phoma strasseri conidia was undertaken using scanning and transmission electron microscopy to examine the host-parasite relationship. Pathogenicity experiments demonstrated that all tested $P$. strasseri isolates had infected the stems and rhizomes of peppermint. Of all inoculation methods, direct placement of colonized agar plugs on damaged epidermis and soaking stems and rhizomes in conidial suspension were the most effective. The behavior of the conidia deposited on the stems and rhizomes was investigated at different time intervals after inoculation: 6, 16, 24, 36 and $48 \mathrm{~h}$. Conidia produced an appressorium directly at the end of a short germ tube. Appressoria were formed over the cuticle, but never over stomata. Direct penetration to host tissue through the cuticle was observed. The spore and hyphae were covered with a mucilaginous sheath.

Ke y words: Mentha piperita, black stem and rhizomes rot, infection process, SEM, TEM

\section{Introduction}

Black stem and rhizomes rot of peppermint (Mentha piperita L.), also called phomosis of mint, is caused by Phoma strasseri Moesz (Boerema et al., 2004). The occurrence of this disease has been so far found in the United States (Horner, 1971; Farr et al., 1995), in Japan (De Gruyter et al., 2002), in India (Kalra et al., 2004), in Hungary (Paizs and Naggy, 1975) and in Poland (Zimowska and Machowicz-Stefaniak, 2005; Zimowska, 2007). The disease symptoms on the plants of peppermint cultivated in the field are visible on the stems, first in the form of necrotic, slightly hollow spots enfolding the stem around. With time, the tissue in the place of the spots gets rotten. Such symptoms are most often formed just under the ground surface to the height up to $10 \mathrm{~cm}$ from the base. The secondary symptom is the reddening or reduction of the leaf blades. Very young stems usually die out without any secondary symptoms of the disease (Horner, 1971; Zimowska, 2007). The rot proceeds very fast on the rhizomes. Young rhizomes rot away wholly, while the bark layer often comes off on older ones (Horner, 1971; Zimowska, 2007). The symptoms on peppermint cultivated in a glasshouse are similar to those that are observed in the field, with no secondary symptoms in the form of the reddening and reduction of the leaves, however (Horner, 1971). The yield losses as a result of plant infection can even reach 90\% (Horner,
1971). Etiological signs in the form of pycnidia, including the conidia of P. strasseri, occur on the stems and rhizomes with the symptoms of black rot (Zimowska and Machowicz-Stefaniak, 2005; Zimowska, 2007).

The accessible literature provides information on disease symptoms caused by P. strasseri (Horner, 1971; Paizs and Naggy, 1975; Zimowska, 2007), biotic interactions of $P$. strasseri with the fungi colonizing the phyllosphere of peppermint stems and rhizomes as well as the effect of the thermal conditions on the formation of the infection material by the fungus (Zimowska, 2011a). The histopathological and ultrastructural aspects of the infection of peppermint by P. strasseri has not been so far documented. Hence, the present research undertakes studies on the ultrastructure of the inoculated stems and rhizomes of peppermint with the aim of explaining the relation between P. strasseri and the host plant.

\section{Experimental}

\section{Material and Methods}

Fungal isolates. The studies used one-spore cultures of three isolates of P. strasseri obtained from the naturally infected plants of peppermint with the signs of black stem and rhizomes rot from the production plantations situated in the south-eastern part of Poland (Zimowska, 2007) and isolate CBS. 126.93

\footnotetext{
* Corresponding author: B. Zimowska, Department of Plant Pathology and Mycology, University of Life Sciences, Poland; e-mail: beata.zimowska@up.lublin.pl
} 
obtained from Centraalbureau voor Schimmelcultures, Utrecht Netherlands.

Inoculation techniques. Isolates of $P$. strasseri were incubated on a maltose agar MA throughout the first week at the temperature of $22^{\circ} \mathrm{C}$ without any light access, and then for 13 hours in ultraviolet light (UV). After that, the isolates were incubated in the same conditions as in the first week of the culture (De Gruyter and Noordelos, 1992). Three methods of inoculation were used to prove the pathogenicity. The first method used plugs of the colonized agar ( $5 \mathrm{~mm}$ diameter) cut out from 2-week-old cultures of each isolate. Those plugs were placed at the stem and rhizome fragments which were disinfected on the surface by being immersed for 60 seconds in 10\% sodium hypochlorite. In the second method, colonized plugs were placed at disinfected fragments of stems and rhizomes, together with the epidermis injured with a needle puncture (Zimowska, 2004). The third method used a suspension of conidia with the density of $10^{6}$ conidia per $1 \mathrm{ml}$. It was obtained by rinsing the surface of the cultures of particular isolates with sterile distilled water. The disinfected fragments of stems and rhizomes were soaked in the suspension for $5 \mathrm{~min}$ utes (Horner, 1971). Each method was tested in humidity chambers. Those were $9 \mathrm{~cm}$ diameter Petri dishes, laid with three layers of cellulose tissue and one layer of filter paper moistened with $4 \mathrm{ml}$ of distilled sterile water (Zimowska, 2004). For each method 120 fragments of stems and rhizomes were used. Control fragments of stems and rhizomes were inoculated with sterile agar plugs (methods I and II) or sterile water (method III). The experiment was conducted twice. Humidity chambers were kept in a thermostat at the temperature of $22^{\circ} \mathrm{C}$ for 12 days. During that time, observations were made every 3 days on the development of disease symptoms. After 12 days, the infection index was calculated on the basis of the disease scale. Next, all fragments of stems and rhizomes were analyzed for the presence of fungus according to Koch's postulates. The results obtained from the experiment were statistically analyzed using a two-factor variance analysis (Anova) according to SAS program (Snedecor and Cochran, 1982).

Sample preparation for scanning electron microscope (SEM). Fragments of stems and rhizomes inoculated by conidial suspension were cut into $2-3 \mathrm{~mm}$ sections. Next, the specimens were fixed with $4 \%$ glutaraldehyde for 3 hours at room temperature and then, for 24 hours, at $5^{\circ} \mathrm{C}$. After that time, the specimens were placed in $1 \%$ cacodylate buffer for 2 hours at room temperature (Kulik, 1988). Next, the specimens were dehydrated in an alcohol series (30\%, 50\%, 70\%, $95 \%$ and $100 \%$, for 15 minutes at each concentration. The specimens were then dried in liquid $\mathrm{CO}_{2}$ by using a BAL-TEC CPD 030 Critical Point Dryer, and finally gold sputter-coated. Observations of six samples were carried out at different time intervals after inoculations: $6,16,24,36$ and 48 hours. Micrographs were obtained using a Vega 2, Tescan scanning electron microscope.

Sample preparation for transmission electron microscope (TEM). The specimens were fixed with $4 \%$ glutaraldehyde for 2 hours at room temperature and post-fixed in $2 \%$ osmium tetroxide in phosphate buffer for 2 hours at $20^{\circ} \mathrm{C}$. The following fixation was conducted in $0.1 \mathrm{M}$ cacodylate buffer at $\mathrm{pH} 7.4$ for 2 hours at $4^{\circ} \mathrm{C}$. Afterwards, the specimens were double-rinsed for 5 minutes in the same buffer and then for another 5 minutes in distilled water. After rinsing, the specimens were post-fixed in $0.5 \%$ uranyl orthosilicate dihydrate solution for 2 hours at room temperature (Maurin et al., 1993). Next, they were dehydrated in an alcohol series (30\%, 50\%, 70\%, $95 \%$ and $100 \%$, for 15 minutes at each concentration at $4^{\circ} \mathrm{C}$, followed by $90 \%, 95 \%$ and $100 \%$ for 15 minutes at each concentration at room temperature). Then, ethyl alcohol was replaced with propylene oxide. After absolute alcohol, the specimens were placed in increasing concentrations of propylene oxide in alcohol: $33 \%$ for $10 \mathrm{~min}$., $50 \%$ for $10 \mathrm{~min}$., $67 \%$ for $10 \mathrm{~min}$, and $100 \%$ twice for $10 \mathrm{~min}$. (Maurin et al., 1993). Next, the specimens were hardened with increasing concentrations of Spurr Low Viscosity resin in propylene oxide: $33 \%$ for 1 hour, $50 \%$ for 1 hour, $67 \%$ for 1 hour, and $100 \%$ for 1 hour. Next, the specimens were placed in polyethylene capsules (filled with resin) and left for 12 hours at $70^{\circ} \mathrm{C}$ in order to polymerize. After the polymerization, the specimens were cut into ultra-thin $85-\mathrm{nm}$ sections by using a Reichert Ultracut $\mathrm{S}$ microtome. Next, they were dyed with $8 \%$ uranyl acetate solution in $0.5 \%$ acetic acid for $45 \mathrm{~min}$. Finally, they were compounded with lead citrate for $10 \mathrm{~min}$. (Maurin et al., 1993).

The materials were examined by means of a FEI Tecnai Spirit $G^{2}$ microscope, operating at an acceleration voltage of $100 \mathrm{kV}$.

\section{Results}

Pathogenicity of isolates to stems and rhizomes of peppermint and inoculation techniques. All studied isolates of $P$. strasseri caused signs in the form of necrosis and then rot on the inoculated fragments of stems and rhizomes. As early as already 3 days after the inoculation, symptoms were observed on peppermint parts inoculated according to method II. Those were necrotic spots, 3 to $10 \mathrm{~mm}$ long, around the infection site. After 6 days, the necrosis grew and covered from $25 \%$ to $30 \%$ of the area of the inoculated parts. After that time, the softening of the tissues in the place of the necrosis could be seen. After 9 days, the rot covered from $40 \%$ to $70 \%$ of the surface of the stems and rhizomes, and after 12 days - from $90 \%$ to $100 \%$ of the surface of the 
Table I

Pathogenicity of Phoma strasseri to stems and rhizomes of peppermint using various inoculation methods (means for 4 isolates)

\begin{tabular}{|c|c|c|}
\hline \multirow{2}{*}{ Inoculation method } & \multicolumn{2}{|c|}{ Infection index (\%) after 12 days $^{x}$} \\
\hline & stems & rhizomes \\
\hline Colonized plugs placed at non-injured epidermis & $87.92 \mathrm{a}$ & $84.38 \mathrm{a}$ \\
\hline Untreated & 0 & 0 \\
\hline Colonized plugs placed at injured epidermis & $96.67 \mathrm{~b}$ & $96.67 \mathrm{~b}$ \\
\hline Untreated & 0 & 0 \\
\hline Stems and rhizomes soaked in conidial suspension $\left(1 \times 10^{6}\right.$ conidia $\left./ \mathrm{ml}\right)$ & $94.79 \mathrm{~b}$ & $95.00 \mathrm{~b}$ \\
\hline \multirow[t]{2}{*}{ Untreated } & 0 & 0 \\
\hline & $\mathrm{HSD}=3.0537$ & $\mathrm{HSD}=3.1825$ \\
\hline
\end{tabular}

${ }^{x}$ Infection index evaluated on the basis of 5 - degree disease scale: $0^{\circ}$ - lack of disease symptoms; $1^{\circ}-$ sign of necrosis visible only around the inoculation point; $2^{\circ}-25 \%$ to $50 \%$ surface of inoculated organs showed disease symptoms; $3^{\circ}-51 \%$ to $75 \%$ surface of inoculated organs showed disease symptoms; $4^{\circ}-76 \%$ to $100 \%$ surface of inoculated organs showed disease symptoms

Values marked with the same letter do not differ significantly HSD - Honest Significant Difference

inoculated parts of peppermint covered with the rot. The development of disease symptoms on peppermint stems and rhizomes inoculated according to method III was similar. In the combination with inoculation through the undamaged epidermis (method I), a trace of necrosis was seen after 6 days around the inoculation site. After 6 days, necrosis accompanied by the softening of the tissues covered from 15 to $20 \%$ of the surface of the inoculated parts. After 12 days, from $70 \%$ to $90 \%$ of the stem and rhizome surface of the inoculated parts was covered with the rot. The symptoms were similar to those observed on the plants of peppermint in the conditions of field cultivation. The most effective methods of inoculation proved to be methods II and III. Values of the infection index were, respectively, $96.67 \%$ and $94.79 \%$ for the stems and $96.67 \%$ and $95.00 \%$ for the rhizomes and they were significantly different from values of the index obtained for method I (Table I). The highest values of the infection index in all inoculation

Table II

Effect of inoculation of Phoma strasseri isolates on occurrence of black stem and rhizomes rot - method I (mean of 6 replications)

\begin{tabular}{|l|c|c|c|c|}
\hline \multirow{2}{*}{ Isolate } & \multicolumn{2}{|c|}{$\begin{array}{c}\text { Infection index (\%) } \\
\text { after 12 days }\end{array}$} & \multicolumn{2}{c|}{ Reisolation $(\%)^{\mathrm{y}}$} \\
\cline { 2 - 5 } & stems & rhizomes & stems & rhizomes \\
\hline M 126 & $88.33 \mathrm{ab}$ & $84.17 \mathrm{a}$ & 100 & 100 \\
\hline M 289 & $82.50 \mathrm{a}$ & $77.50 \mathrm{a}$ & 100 & 100 \\
\hline CBS.126.93 & $88.33 \mathrm{ab}$ & $81.67 \mathrm{a}$ & 100 & 100 \\
\hline M 743 & $92.50 \mathrm{~b}$ & $94.17 \mathrm{~b}$ & 100 & 100 \\
\hline Untreated & 0 & 0 & 0 & 0 \\
\hline & HSD $=8.7309$ & HSD $=9.1322$ & \multicolumn{3}{|c|}{} \\
\hline
\end{tabular}

Note: see table I.

${ }^{\mathrm{Y}}$ For stems and rhizomes showing black rot symptoms, percent isolations that resulted in P. strasseri colonies. methods among the tested isolates were for isolate M 743 (Tables II, III, IV). Generally, those values did not significantly differ from the values of the index obtained for the other isolates, except isolates M 289 and M 126 tested according to method II (Table III), the same isolates and isolate CBS. 12693 , which were

\section{Table III}

Effect of inoculation of Phoma strasseri isolates on occurrence of black stem and rhizomes rot - method II (mean of 6 replications)

\begin{tabular}{|l|c|c|c|c|}
\hline \multirow{2}{*}{ Isolate } & \multicolumn{2}{|c|}{$\begin{array}{c}\text { Infection index (\%) } \\
\text { after } 12 \text { days }^{\mathrm{x}}\end{array}$} & \multicolumn{2}{c|}{ Reisolation (\%) } \\
\cline { 2 - 5 } & stems & rhizomes & stems & rhizomes \\
\hline M 126 & $95.00 \mathrm{ab}$ & $90.33 \mathrm{a}$ & 100 & 100 \\
\hline M 289 & $90.50 \mathrm{a}$ & $95.83 \mathrm{ab}$ & 100 & 100 \\
\hline CBS. 126.93 & $99.17 \mathrm{bc}$ & $98.33 \mathrm{ab}$ & 100 & 100 \\
\hline M 743 & $100.00 \mathrm{~b}$ & $100.00 \mathrm{~b}$ & 100 & 100 \\
\hline Untreated & 0 & 0 & 0 & 0 \\
\hline & $\mathrm{HSD}=8.6408$ & $\mathrm{HSD}=9.0047$ & & \\
\hline
\end{tabular}

Note: see tables I and II

Table IV

Effect of inoculation of Phoma strasseri isolates on of occurrence black stem and rhizomes rot - method III (mean of 6 replications)

\begin{tabular}{|l|c|c|c|c|}
\hline \multirow{2}{*}{ Isolate } & \multicolumn{2}{c|}{$\begin{array}{c}\text { Infection index (\%) } \\
\text { after } 12 \text { days }^{\mathrm{x}}\end{array}$} & \multicolumn{2}{c|}{ Reisolation (\%) } \\
\cline { 2 - 5 } & stems & rhizomes & stems & rhizomes \\
\hline M 126 & $91.67 \mathrm{ab}$ & $92.50 \mathrm{a}$ & 100 & 100 \\
\hline M 289 & $90.83 \mathrm{a}$ & $92.50 \mathrm{a}$ & 100 & 100 \\
\hline CBS. 126.93 & $97.50 \mathrm{ab}$ & $96] .67 \mathrm{a}$ & 100 & 100 \\
\hline M 743 & $99.50 \mathrm{~b}$ & $98.33 \mathrm{a}$ & 100 & 100 \\
\hline Untreated & 0 & 0 & 0 & 0 \\
\hline & $\mathrm{HSD}=8.7408$ & $\mathrm{HSD}=9.8573$ & & \\
\hline
\end{tabular}

Note: see tables I and II 


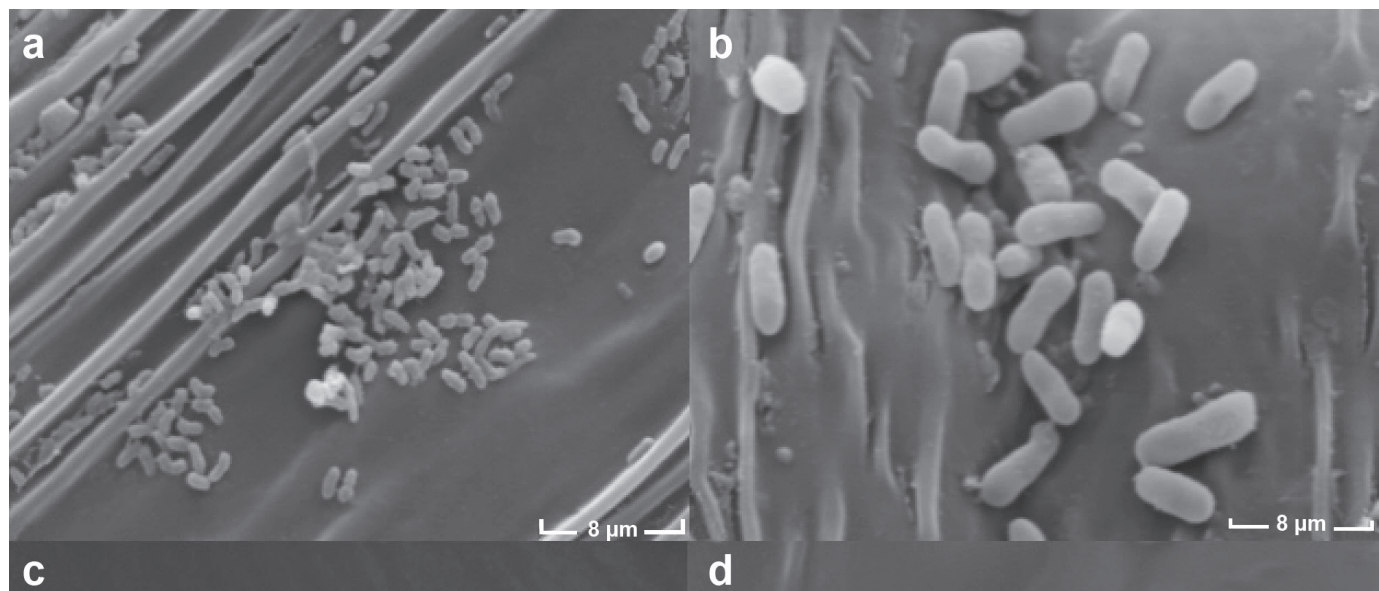

C

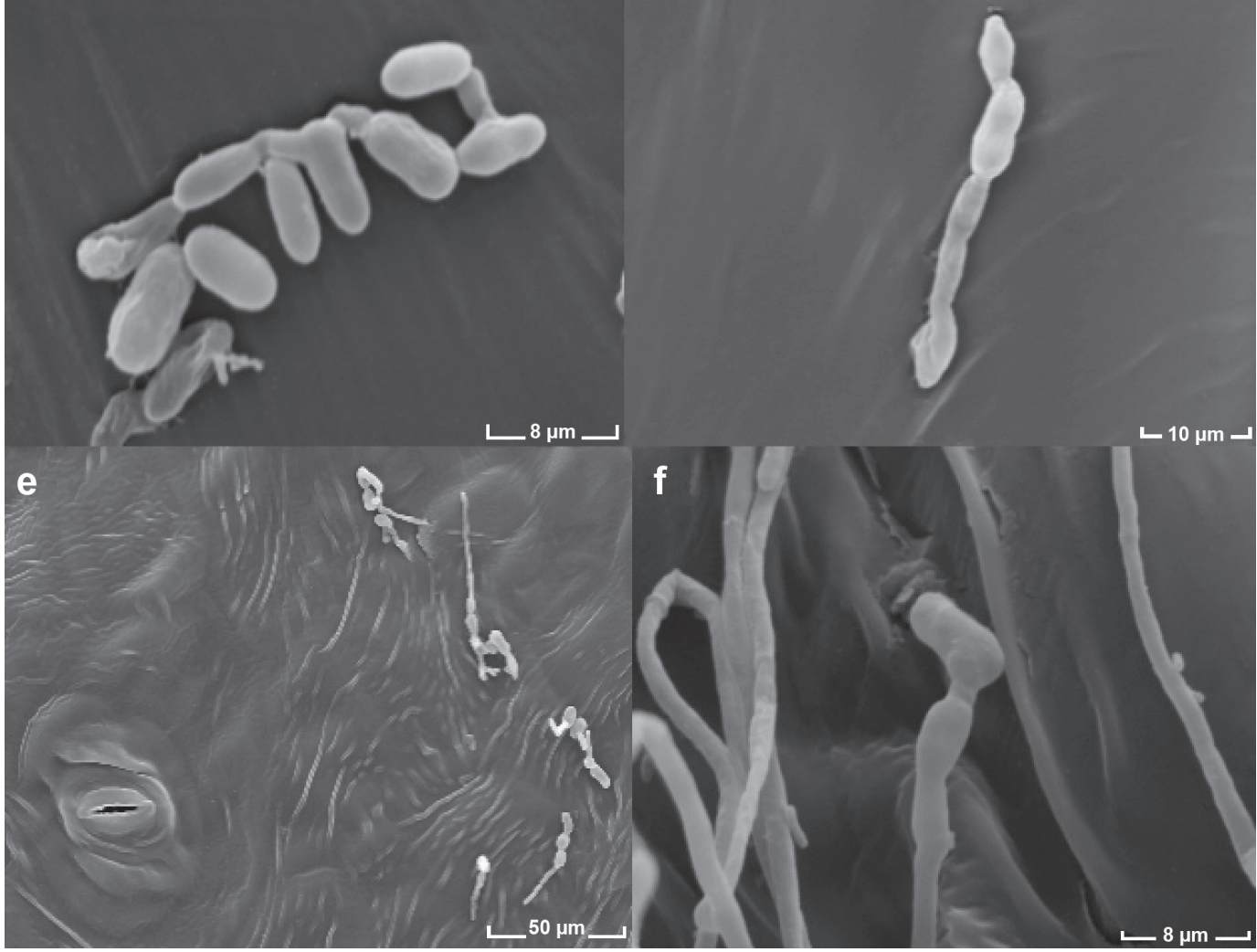

Fig. 1. Scanning electron micrographs of Phoma strasseri on peppermint stems and rhizomes.

(a, b), view of pycniospores $6 \mathrm{~h}$ after inoculation (scale bar $=8 \mu \mathrm{m})$. (c), germinated spores $16 \mathrm{~h}$ after inoculation $(\mathrm{scale}$ bar $=8 \mu \mathrm{m})$. $(\mathrm{d})$, adhesion structure in the form of appressorium on the end of germ tube $24 \mathrm{~h}$ after inoculation (scale bar $=10 \mu \mathrm{m})$. (e), development of appressoria and germinating of spores were present in some distance of the stomata (scale bar $=50 \mu \mathrm{m}$ ). (f), development of hyphae at the surface of cuticle $36 \mathrm{~h}$ after inoculation (scale bar $=8 \mu \mathrm{m})$. (Photo. M. Wróbel)

used to inoculate the rhizomes tested according to method I (Table II) and isolate M 289, used to inoculate the stems in method III (Table IV). P. strasseri cultures were reisolated from all inoculated organs, for all methods (Tables II, III, IV). Morphological features of reisolated cultures corresponded to the features of cultures considered in the research. Uninoculated con- trols remained symptomless, and results from the two experiments were similar.

Scanning electron microscope. Six hours after inoculation, conidia of $P$. strasseri were visible on the surface of peppermint stems and rhizomes (Fig. $1 \mathrm{a}, \mathrm{b}$ ). After 16 hours, single conidia formed germ tubes of length not exceeding $5 \mu \mathrm{m}$ (Fig. 1c). Twenty four hours 


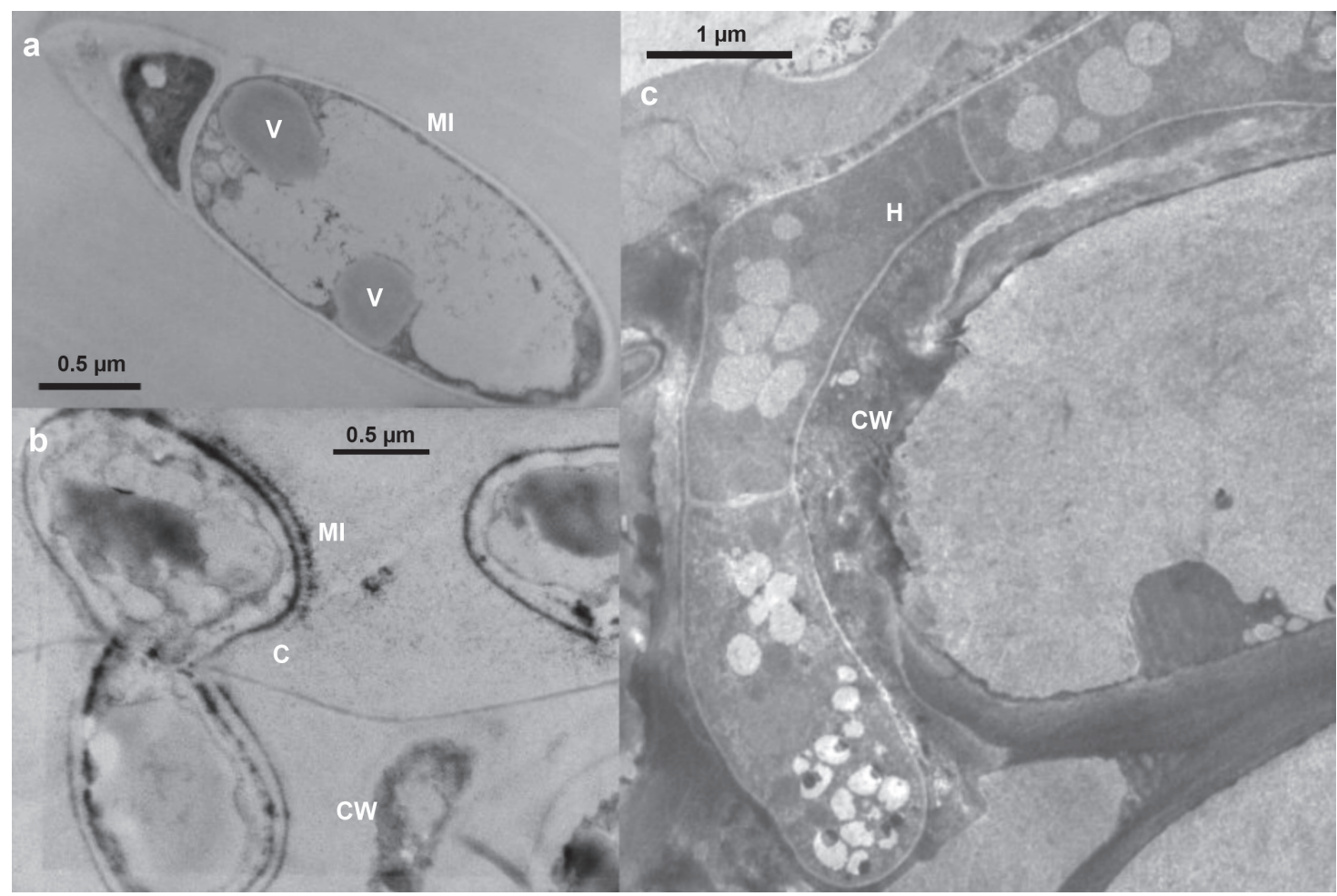

Fig. 2. Transmission electron micrographs of Phoma strasseri on peppermint stems and rhizomes.

(a), germinating and highly vacuolated $(\mathrm{V})$ Phoma strasseri spore with the mucilaginous layer $(\mathrm{Ml})$ present on the wall $(\mathrm{scale}$ bar $=1 \mu \mathrm{m})$. (b), direct penetration through the cuticle $(\mathrm{C})($ scale bar $=1 \mu \mathrm{m})$. (c), expanding septate hyphae $(\mathrm{H})$ within the cell wall $(\mathrm{CW})(\mathrm{scale}$ bar $=1 \mu \mathrm{m})$. (Photo. M. Rudaś)

after inoculation, an adhesive structure in the form of an appressorium was seen at the end of the germ tube (Fig. 1d). Conidia germination and appressorium formation always took place at a certain distance from the stomata (Fig. 1e). After 36 hours, unbranched hyphae were observed on the surface of the cuticle of peppermint stems and rhizomes (Fig. 1f).

Transmission electron microscope. The conidia of P. strasseri germinating on the surface of the cuticle had big vacuoles (Fig. 2a). A layer of a mucilaginous sheath not greater than $0.3 \mu \mathrm{m}$ thick was visible on the surface of the cell wall of the conidia (Fig. 2a). Direct penetration of the pathogen by the cuticle of the host plant was observed between 36 and 48 hours after inoculation. A sheath of a mucilaginous substance $\mu \mathrm{m}$ was present on the surface of the wall of the hyphae (Fig. 2b). After 48 hours, septate hyphae was visible in epidermis cells (Fig. 2c).

\section{Discussion}

Pathogenicity studies showed that all tested isolates of P. strasseri caused infection of the inoculated stems and rhizomes of peppermint. This is testified to by high values of infection indexes and the fulfillment of Koch's postulates. Of all methods of inoculation, the most effective proved to be the one consisting in placing plugs of colonized agar on the injured tissue of the stems and rhizomes, and the method considering soaking of the fragments in a conidial suspension. These results are consistent with information from literature, according to which the enumerated inoculation methods also proved the most effective for other facultative pathogens such as Phoma linguam, (Sock and Hoppe, 1999), P. exigua (Koike et al., 2006), P. exigua var. foveata (Giebel and Dopierała, 2004) and P. multirostrata (Garibaldi et al., 2010). The fact that the disease symptoms on the inoculated peppermint parts are similar to those that are observed in the conditions of field cultivation is certainly related to the production of pectolytic enzymes, especially polygalacturonase and maceration enzymes, by P. strasseri (Melouk and Horner, 1972a). It follows from studies conducted by Melouk and Horner (1972b) that enzymes of P. strasseri show the greatest activity 5 days after infection. Studies confirm the thesis posed by American researchers because already after 6 days, the symptoms of tissue softening were visible on inoculated fragments of stems and rhizomes. 
Studies of the ultrastructure of the inoculated stems and rhizomes of peppermint with an conidial suspension pointed to the formation of an adhesive structure at the end of the germ tube in the form of an appressorium and to the direct infection of the pathogen by the cuticle. The ability of fungi for active infection is connected with the fact that they form special structures by means of which they first get attached to the host plant, after which they penetrate its tissues. This is an important condition of successful infection and next the development of a disease (Kulik, 1988; Maurin, 1993). It follows from the present studies that the germinating conidia of P. strasserii were fixed to the surface of peppermint stems and rhizomes by means of the appressorium. It has been known for long that in the majority of fungi the formation of the appressorium at the end of the germ tube takes place as a result of a mechanical contact of the fungus with the substrate (Büsgen, 1893; Kerchung and Hoch, 1995). The formation of the appressorium was found in the species closely related to genus Phoma, i.e. P. exigua var. linicola (Roustaee et al., 2000), Ascochyta pisi (Heath and Wood, 1969), A. fabae (Maurin et al., 1993) and A. rabiei (Pandey et al., 1987). In P. strasseri, the germinating conidia were also attached to the surface of stems and rhizomes by means of a mucilaginous sheath that covered the wall of the conidia and the hyphae. The presence of the mucilaginous sheath was observed during the studies on conidiogenesis of P. strasseri (Zimowska, 2011b). It is formed at the last stage of differentiation of the conidia wall to its final structure (Boerema and Bollen, 1975). Many fungi species that perform the infection directly through the cuticle form this type of mucilaginous exudates. It occurs, for example in Phyllosticta amplicida (Kerchung and Hoch, 1995), Phomopsis phaseoli (Kulik, 1988) and Phoma macdonaldii (Roustaee et al., 2000). Its role is to strengthen the contact with the host plant. Besides, it seals up the site where the infection hyphae penetrates and it protects the appressorium from drying out and from unfavourable atmospheric conditions (Roustaee et al., 2000). The studies pointed to a direct penetration of P. strasseri by the cuticle of peppermint stems and rhizomes omitting the stomata. The majority of fungi penetrate into the tissues of their hosts directly through the cuticle. This model of infection is usually accompanied by the formation of the appressorium (Kulik, 1988). Direct penetration was observed for example in Phomopsis scabra (Ammon and Vann, 1994), Colletotrichum lagenarium (Bonnen and Hammerschmidt, 1989) and in C. gloeosporioides (Dickman et al., 1982). It is known that direct penetration of pathogenic fungi occurs as a result of the joint action of two factors, namely the mechanical pressure of a fast growing infection hyphae and the enzymes decomposing cutin and then pectin compounds and cellulose making the composition of the cell wall (Isaac, 1992). In the case of P. strasseri, pectolytic and maceration enzymes produced by the pathogen certainly take part in the process of active penetration. The involvement of pectolytic and hemicellulolytic enzymes has been reported for P. linguam (Hammond et al., 1985). The presence of P. strasseri hyphae in epidermis cells as early as after 48 hours can point to a short period of the pathogen incubation.

\section{Literature}

Ammon V. and S.R. Vann. 1994. Scanning electron microscopy of sycamore pathogens on inoculated leaves. Tech. Bull. Miss. Agric. For. Exp. Station 196: 6.

Boerema G.H. and G.J. Bollen. 1975. Conidiogenesis and conidial septation as differentiating criteria between Phoma and Ascochyta. Persoonia 8: 111-144.

Boerema G.H., J. De Gruyter, M.E. Noordeloos and M.E.C. Hamers. 2004. Phoma identification manual. Differentiation of specific and infra-specific taxa in culture. CABI Publising., 470 pp.

Bonnen A.M. and R. Hammerschmidt. 1989. Cutinolytic enzymes from Colletotrichum lagenarium. Physiol. Mol. Plant Pathol. 35: 463-474.

Büsgen M. 1893. On some properties of the sporelings of parasitic fungi. Bot. Z. 51: 53-72.

De Gruyter J. and M.E. Noordeloos. 1992. Contributions towards a monograph of Phoma (Coelomycetes) - I. 1. Section Phoma: Taxa with very small conidia in vitro. Persoonia 15: 71-92.

De Gruyter J., G.H. Boerema and A. Van der Aa. 2002. Contributions towards a monograph of Phoma (Coelomycetes) VI-2. Section Phyllostictoides: Outline of its taxa. Persoonia 18: 1-53.

Dickman M.B., S.S. Patil and P.B. Kolattukudy. 1982. Purification and characterization and role in infection of an extracellular cutinolytic enzyme from Colletotrichum gloeosporioides on Carica papaya. Physiol. Plant Pathol., 20: 333-347.

Farr D.F., G.F. Bills, P.G. Chamurius and Y.A. Rossman. 1995. Fungi on plants and plant products in the United States. American Phytopath. Society.

Garibaldi A., G. Gilardi and M.L. Gullino. 2010. First report of leaf spot caused by Phoma multirostrata on Fuchsia x hybrida in Italy. Plant Dis. 94, 3: 382.

Giebel J. and U. Dopierała. 2004. Pathogenesis of potato gangrene caused by Phoma exigua var. foveata: II. Activities of some hydrolases and dehydrogenases. J. Phytopathol. 152, 7: 399-403.

Hammond K.E., B.J. Lewis and T.M. Musa. 1985. A systemic pathway in the infection of oilseed rape by Leptosphaeria maculans. Plant Pathol. 34: 557-565.

Heath M.C. and R.K.S. Wood. 1969. Leaf spots induced by Ascochyta pisi and Mycosphaerella pinnodes. Ann. Bot. 33: 657-670. Horner C.E. 1971. Rhizome and stem rot of peppermint caused by Phoma strasseri. Plant Disease Reporter, 55: 814-816.

Isaac S. 1992. Fungal-Plant Interactions. Chapman and Hall, London. Kalra A., H.B. Singh, R. Pandey, A. Samad, N.K. Patra and S. Kumar. 2004. Diseases in mint: causal organisms, distribution and control measures. J. of Herbs, Species \& Medicinal Plants 11: 71-91. Kerchung K. and H.C. Hoch. 1995. Visualization of the extracellular matrix surrounding pycnidiospores, germlings and appressoria of Phylosticta amplicida. Mycologia 87: 759-771.

Koike S.T., K.V. Subbarao, G.J.M. Verkley, D. Fogle and T.M. O'Neill. 2006. Phoma basal rot of romaine lettuce in California caused by Phoma exigua: Occurrence, characterization and control. Plant Dis. 90: 1268-1275. 
Kulik M.M. 1988. Observation by scanning electron and brightfield microscopy on the mode of penetration of soybean seedlings by Phomopsis phaseoli. Plant Dis. 72: 115-118.

Maurin N., J.P. Gouuret and B. Tivoli. 1993. Histopathology of the interaction between Ascochyta fabae and Vicia fabae: Comparsion of susceptible and resistant reactions. Agronomie 13: 921-927.

Melouk H.A. and C.E. Horner. 1972a. Production of pectolytic and macerating enzyme by Phoma strasseri. Can. J. Microbiol. 18: 1065-1072.

Melouk H.A. and C.E. Horner. 1972b. Growth in culture and pathogenicity of Phoma strasseri to peppermint. Phytopathology, 62: 575-576.

Paizs L. and F. Naggy. 1975. Phoma strasseri: A new pathogen of mint in Hungary. Herba Hungarica, 14: 65-75.

Pandey B.K., U.S. Singh and S.H. Chaube. 1987. Mode of infection of Ascochyta blight of chickpea caused by Ascochyta rabiei. J. Phytopathol., 119: 88-93.

Roustaee A., G. Dechamp-Guillaume, B. Gelie, C. Savy, R. Dargent and G. Barrault. 2000. Ultrastructural studies of the mode of penetration by Phoma macdonaldii in sunflower seedlings. Phytopathology 90: 915-920.
Snedecor G.W. and G.W. Cochran. 1982. Statistical Methods. The Iowa State Univ. Press, Ames, Iowa, 122 pp.

Sock J. and H.H. Hoppe. 1999. Pathogenicity of sirodesmin-deficient mutants of Phoma lingam. J. Phytopathol. 147: 169-173.

Zimowska B. 2004. Studies on the pathogenicity of Seimatosporium hypericinum (Ces.) Sutton for the leaves, stems and seeds of St. John's wort (Hypericum perforatum L.). Herba Pol., 50: 145-151.

Zimowska B. 2007. Fungi colonizing and damaging different parts of peppermint (Mentha piperita L.) cultivated in South-Eastern Poland. Herba Pol. 53 (4): 97-105.

Zimowska B. 2011. Biotic activity of Phoma strasseri and the effect of thermal conditions on the growth and formation of the pathogens infectious material. Acta Sci. Pol. Hortorum Cultus, 10, 3: 213-224. Zimowska B. 2011b. Conidiogenesis of Phoma strasseri the fungus responsible for black stem and rhizomes rot in peppermint (Mentha piperita). Acta Sci. Pol. Hortorum Cultus, 10, 4: 171-178.

Zimowska B. and Machowicz-Stefaniak Z. 2005. Charakterystyka izolatów Phoma strasseri nie notowanego w Polsce patogena mięty pieprzowej (Mentha piperita L.). [Characteristics of Phoma strasseri isolates not reported in Poland pathogen of peppermint (Mentha piperita L.)]. Acta Agrobot. 58 (2): 151-162. 